\title{
Discussion on the Countermeasures of the development of sports
}

\section{economy in China}

\author{
Xianlong Lei \\ Jiangxi Institute of Economic Administrators,Jiangxi,Nanchang,330088
}

Key words: sports economy, commercialization, problems, countermeasures

\begin{abstract}
: with the continuous improvement of people's awareness of fitness, the development of sports economy has become more and more open, and even has become an important part of the national economy. However, due to the short time of the development of sports economy in China, there are still some problems that can not be ignored, which has attracted wide attention from all walks of life. The author on the basis of previous studies, combined with personal investigation, systematic analysis of the current situation and existing problems of our country sports economic and commercial development, points out the corresponding countermeasure, in order to promote the rapid development of sports economy in our country.
\end{abstract}

Modern sports is a product of Western society, with the development of modern western society, the original game of sports and the pursuit of high economic interests of the business more and more closely linked together. Economic interest groups not only have the sports goods industry, but also almost monopolized the construction and operation of sports facilities, the use of sports to maximize their profits. The rapid development of economy has laid the foundation for the commercialization of sports. Due to the formation and development of the commercialization of sports, and the emergence of professional sports, which pay great attention to the return of material, the physical education has changed in different degrees. Below, we have a number of issues related to the commercialization of sports.

\section{Analysis on the necessity of the commercialization of sports economy}

\section{1、Commercial sports economy is conducive to the prosperity of sports}

1976, the modern Olympic movement has experienced 80 years of glorious and arduous process, the people from the plight of the difficulties, only the United States, Losangeles, a bid to apply for. One of the most embarrassing to the International Olympic Committee is the pressure of public opinion: the Olympic Games is a Lost Lady and the sale of the soldiers. Experts cite the following facts: in 1972, Germany, Munich City, due to host the twentieth Olympic Games and the great financial difficulties. In 1976, the twenty-first Montreal Olympic Games, a loss of \$10, less than years to pay off the debt. 1980, the twenty-second Olympic Games in Moscow, the former Soviet Union, a total cost of \$about 9000000000. The Losangeles City Council held a meeting after the Olympic Committee decided to hold a meeting to discuss whether the municipal government should host the Olympic Games. Unfortunately, the experts made refused to use the fiscal revenue decision to host the Olympic games. The global Olympic movement faces the crisis of abortion. Come forward to break the deadlock is the famous American entrepreneur Ueberroth. His private enterprise financing hosted by reversing the Olympic Games the fate of the universe, and the 23rd Olympic Games in Los Angeles will become the global Olympic movement to promote local economic development model. In 1984 the Olympic Games not only did not have a loss, but also made a profit of \$. Since the Olympic movement presents a thriving scene: the 1988 Seoul Olympic 
Games will race in 160 (Beamon Montreal Olympic Games more than 72), 8143 athletes, spending $\$ 3$ billion, but profit 4.97 billion. There are 140 countries and regions of the 226 television stations for the Seoul Olympic Games were broadcast, the total number of ratings was 4 billion. 1981 only Seoul and Nagoya two cities compete in the 1988 Summer Olympic Games, 1986 has 6 cities competing for the 1992 Olympic Games, for 1996 and 2000 Olympic Games in and the city has 6. The race to host the 2004 Olympic Games city has as many as 11! Each city on the bid for the summer and Winter Olympic Games. These are enough to show that the commercialization of sports has brought unprecedented opportunities for sports.

\section{2、 Sports economy commercialization also caused the trend of global economic integration}

In the economic globalization has been an irresistible today, cross-border trade, service trade and international capital flows and the enhancement of technology widely spread quickly, the economy of countries all over the world strengthen the interdependence and the world economy toward a more open to market, the world economy tends to be integrated. Under such conditions, any enterprises, businesses without choice must in the face of this trend, and the enterprise to establish the international image of their own, the products become international brands, it should make full use of the attention of the world of sports and the business opportunities brought about by the. Such as the use of the image of the Olympic -- compensation for the use of its intellectual property, i.e. the sponsorship and franchise business model, make their own brands of enterprises and products to achieve the most significant global impact with the help of dissemination of tremendous Olympic Games, the Olympic Games will become one of the most value of options. Therefore, the commercialization of sports economy is the result of the trend of global economic integration.

\section{The negative effect of the commercialization of sports economy 1、Directly promote the sports event frequentlyhappening scandal}

The commercialization of sports economy, on the one hand, can let the human have sufficient reason to challenge their own limits, the game scene is more intense and exciting. But on the other hand, athletes in order to achieve excellent results, appeared on the field of doping, competition is unfair, violence, bribery scandal, the problem has been more and more people's attention. In addition, although money can not override the Olympic spirit, but who can not ignore the Olympic Games is a huge economic development of the driving force. The Olympic Games and the economy are connected with each other, and promote each other, it is a new form of modern economy. But the attendant problem is that the bid to host countries increased year by year, fierce competition. The city committee of bribery, bribes scandals. The Saline Lake City scandal is a case in point.

\section{2、To a certain extent induced loss of competitive sports talents}

To strengthen the communication and cooperation of competitive sports talents is the basic feature of the development of sports in the world today. In the process of the commercialization of competitive sports, the commercial activities are becoming more international, more frequent and more standardized. However, the increasingly strong commercial operation in promoting the development of China's competitive sports vulnerable projects, but also to the stability of our competitive sports teams can not be ignored by the negative impact. Some of the great development potential of the young players or relevant personnel (advantage) in foreign generous material life treatment and training environment of temptation, migrate, and weaken the strength of competitive sports in our country in a certain extent impede the sports industry in China sustained, healthy and stable development of health. 


\section{3、The problem of the disabled athletes}

"Focus on participation" is the slogan of the Olympic Games, but the commercialization of the Olympic Games has been far away from its significance. The commercialization of the Olympic Games has made athletes for Olympic tickets infighting, can in the Olympic Games winning and desperate, to won the gold medal compatriots into beasts of burden. They see the enemy as the enemy, depending on the game is the mall, the lack of peace and love, more is the indifference and hatred. In addition, the training of qualified athletes is more brutal, the amount and intensity of training has been far more than a person can withstand the degree of. Today's competitive sports training is more scientific and systematic than in the past, but it is difficult to bear the intensity of training is still known to make a lot of physical disability, or premature retirement. The crazy amount of large amount of exercise training is not so much to improve the level of competition, it is better to say that in the training of athletes to the extent of pain tolerance. In addition to the regular or excessive use of stimulants, so many athletes in life is almost in pain alive. Olympic athletes is the pride of the world, why go to the point where they might to the interests of the state, but more likely to own short-term utilitarian. Commercialization of the Olympic Games so that the Olympic spirit of utilitarianism, so that the value of the athletes tend to use money to measure everything, the value of money to replace everything, perhaps this is the meaning of gold culture.

\section{Analysis on the Countermeasures of the commercialization of sports economy}

1、Development of various forms of commercial performances and competitions and improve athletic performance skills of ornamental, expand collective project and the proportion of development efforts

"Watch" sports consumption is an important part of sports industry, the improvement of the majority of the audience consumption concept update and the level of consumption laid the competition performance market, at the same time, the reform of competition system in China, subjective and objective format and the club's implementation, and promote the development of competition performance market. Has formed a considerable scale, quite stable audience. Because the motor skills is a highly ornamental athletics sports project, set multi art form combining complex, also sports skills also has art, aesthetic, dynamic, and other relevant characteristics. Combined with the current heavy social pressure of life, environmental depression and emotional tension caused by the spirit of emptiness and other social status quo. Adventure, excitement and adventure sports has become more most people seek the relative increase in athletic skill difficulty, grazing risk degree, stimulating sense has become a competitive survival skills, development and market of essential direction of development. According to changes in the market to improve self-development, skills to be more people to be accepted, the skill movement as a movement of its own vitality will be able to reflect. Therefore, in the tide of the commercialization of sports, to carry out various forms of commercial performances and competitions as a breakthrough in the commercialization of competitive skills at the present stage.

\section{2、To improve the market structure of sports occupation, establish and improve the laws and regulations}

Because of the short time of the professional reform in our country, the club is not very familiar with the market operation law, so the operation performance is not good. At the same time, the operation of the market of sports needs corresponding objective conditions, and the our country still is a developing country, the market economy system has not been fully established and in a certain extent restricts the development of professional sports in China. The ugly phenomenon of sports field frequently occurs, the problem of the disabled athletes are more and more serious and the 
professional sports system of our country is not perfect have a direct relationship. However, our country also has the advantage of developing professional sports. After more than 20 years of reform and opening up, China's economy has considerable improvement, people's living standards generally improved, some areas have to the pursuit of quality of life stage, which is professional sports to provide the corresponding conditions. According to the development experience of American professional sports, it is not always the best way for the club to carry on the simple competition by means of market, which is determined by the characteristics of sports competition products. And our professional club between the malignant competition emerge in endlessly, the lack of ability to macro management of Sports Association in the, in dealing with contradictions and disputes, the lack of authoritative, even mixed with administrative behavior, the professional reform of our country has been hampered. Therefore, we should draw lessons from the experience in the operation of the American professional sports, in the reorganization of the individual sports associations based on, and gradually form a monopolistic competition market, by Single Sports Association of sports events in the overall management, to improve the ability of negotiation, so as to ensure the economic interests of the members of the club are not affected by the loss. Under the control of the association rules and regulations, the professional club develops the market independently, thus forming a "win-win" situation. Professional sports is the management system of sports events through the market mechanism, if the lack of appropriate laws and regulations, will inevitably lead to increased transaction costs. Therefore, we must introduce the various laws and regulations, from the system to ensure the operation of professional sports, and people's awareness of the system to get corresponding improvement, in order to form a habit of abide by the rules of the market, the professional sports can develop in a healthy and orderly manner. In this way, the elimination of the ugly phenomenon of sports field, to solve the problem of disability in the system has a breakthrough in the system.

\section{3、Pay attention to environmental protection, promote the green sports}

Environmental protection is the issue of economic development, but also the most important issue of economic development, the conflict between sports and environment, has become a practical problem that can not be ignored. In 1972, the U. S. city of Danwei under pressure on local ecosystems, and had to cede held the rights of the 12th Olympic Games. In 1974, Vancouver, Canada, in order not to destroy the natural landscape of vegetation damage had to be withdrawn for the thirteenth winter olympics. It is proposed that sports can promote economic development, especially to host the Olympic Games, but not at the expense of the environment for the price, otherwise the loss outweighs the gain. Some countries or regions to economic benefits, build a large number of golf courses, destroyed a large area of green space, for golf course turf insect dispersant a lot into the river, resulting in the destruction of the environment, some developed countries have on this problem have focused on, but in the use of the means of plunder, they in some developing countries built in large numbers golf course, obtain economic benefits, it should be caused by developing countries. The commercialization of sports can not only be placed in the immediate interests, but should pay special attention to environmental protection, resource conservation, efforts to establish an effective and sustainable development of the economic environment and reproduction mechanism.

Now, the reason why commercial competition continue to boom, as well as sports development the reason why more and more commercialized, correct the root cause, or by the sports has a fertile ground for the business of this reality, the so-called sports commercialization but is conform to the reality and trend of the development of the bale. Therefore, it can be said: commercial competition at least in China and more for the development of space, and sports further commercialization is 
undoubtedly sports forward development of the inevitable requirement, so we should let the sports further commercialization.

\section{reference:}

[1] a masterpiece of "sports sports economy" on [J]; sports history; 200104

[2] Wang Minmin; sports wealth theory and sports economy [J]; Journal of PLA Institute of physical education; 200203

[3] Li Ming; on the innovation and practice in the development of Chinese sports economy; [J]; scientific and technological progress and countermeasures; the 07 phase of 2003

[4] Zhang Mingzhu; analysis of social and psychological factors of developing sports economy; [J]; sports and science; the 01 phase of 2003 